\title{
CFD SIMULATION OF FLOW PAST WING BODY JUNCTION: A 3-D APPROACH
}

\author{
SNIGDHA MANDAPUDI ${ }^{1}$, SATYA SANDEEP CHAGANTI ${ }^{2}$, SWATHI GORLE $^{3}$, \\ SHIVA PRASAD. $\mathrm{U}^{4}$, GOVARDHAN. $\mathrm{D}^{5}$ \& PRAVEEN. $\mathrm{B}^{6}$ \\ ${ }^{1,2,3,4,5}$ Assistant Professor, Department of Aeronautical Engineering, Institute of \\ Aeronautical Engineering, Dundigal, Hyderabad, India \\ ${ }^{5}$ Professor, Head of the Department of Aeronautical Engineering, Institute of
} Aeronautical Engineering, Dundigal, Hyderabad, India

${ }^{6}$ Assistant Professor, Department of Aeronautical Engineering, MLR Institute of Technology,

Dundigal, Hyderabad, Telangana, India

\begin{abstract}
Turbulence and flow disturbances occurring at the wing body junction of aircraft causes aerodynamic drag and decreases the performance. The main objective of this work is to modify the design at wing body junction by the addition of different types of fillets and strakes and see if there is any reduction from previously generated drag. The validation of the new design was simulated using CFX where Naiver Stokes equations were solved on the modified design by using suitable turbulence models. These small modifications in design proved to be very efficient. Application of these design changes at wing body junction of commercial aircraft will prove to be highly effective in enhancing flight performance.
\end{abstract}

KEYWORDS: Aerodynamics, Drag Reduction, Fluid Structure Interaction \& CFD

Received: Jul 17, 2017; Accepted: Jul 31, 2017; Published: Aug 03, 2017; Paper Id.: IJMPERDAUG201734

\section{INTRODUCTION}

Aerodynamic drag reduction in the design of the commercial aircraft has always beenthe main trade off for the aircraft designers. The drag created at the wing -body junction is always an area of study, where many design modifications have been implemented to reduce the drag created. Due to the presence of unfavorable pressure gradients, the separation of the boundary layer takes place, creating vortices around the wing, resembling the shape of a horseshoe, known as horseshoe vortex which causes increased drag as seen in figure 1.Performing a CFD simulation to understand the flow phenomena around the wing body junction gives a good idea of the location of the horseshoe vortex formation. Choosing an appropriate turbulence model is important to get accurate simulation results. Gand and his team have investigated on DLR-F6 an industrial design having a less blunt factor. They performed experiments on wind tunnel at Reynolds number at 2.8*105 and compared the results with simulation data delivered via LES and RANS methods. They did not find any corner separation in the experiment, which contradicted with the simulation done in RANS/LES methods, this made them conclude that bluntness factor does not completely guide the junction flow, but controls horseshoe vortex behavior. In the case of rood aerofoil RANS results were less accurate than the LES approach, since LES methods gave close results to the experimental, RANS calculations were efficient in capturing the junction flow to an increase of the incoming boundary layer thickness and increase the angle of attack ${ }^{[1],[7],[8]}$. 


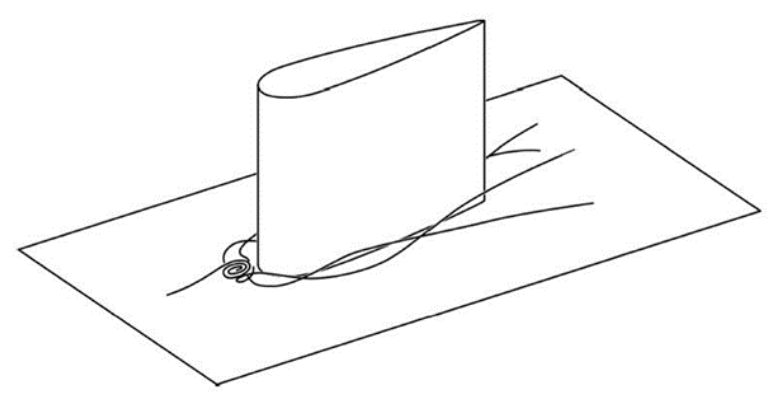

Figure 1: Horseshoe Vortex

W.J Denverport along with his team had conducted research on turbulence structure near the nose of a wing body junction, their investigations have highlighted that at 0.47 wing thickness, and upstream of the wings leading edge and the region of separation had been started. The part of the bimodal flow is kindred with the generation of intense turbulence. The corner between the test walls of the wings leading edge was found to be the area of the dangerousturmoil. ${ }^{[17]}$ Satya Prakash and team concluded that the steady RANS turbulence method gives suitable results compared with the experimental observation. SST K-Omega perfectly estimates the separation region near fuselage wing junction when compared to realizable K-Epsilon model. They also pointed that the reliability of the calculated results is dependent on the number of solver variables such as mesh quality, numerical schemes, convergence criteria. ${ }^{[26]}$ W.J Devenport and R.L Simpson have made the velocity measurements for the flow past through wing body junction. They succeeded to come out with a picture of horse shoe vortex and its three-dimensional turbulence structure around the wing. They validated the experimental results with the numerical results and made a comment that Cebeci-Smith plus the algebraic stress models are among the best to represent the flow phenomena of wing -body junction. ${ }^{[13,21]}$ D.D. Apsley and team also concluded that SST and K-g models gave better simulation results when compared with experimental data for wing body junction. ${ }^{[9]}$ Song $\mathrm{Fu}$ and his team made a conclusion that K-omega model (WDT) is efficient in predicting the flow characteristics of the wing body junction. They also included that with unfavorable pressure gradients DDES model is feasible to visualize large eddies separated from the leading edge. ${ }^{[3]}$ Bryan. C.H had validated the results of computational fluid dynamic code with the experimental deductions for low-speed roods wing junction flow, they found out that giving inflow/outflow boundary conditions in CFD code are producing matching results for the experimental data. Drag reduction because of the stake was not dependent on the Reynolds number. ${ }^{[5]}$ J.H Wong and E.K Png have studied that the flow phenomena of NACA 0020 fixed to the flat surface and compared time averaged LES results on the fine grid and medium grid with improved resolution in the symmetric plane using the conventional Smagorinsky model. They found that dynamic Smagorinsky model is the best to capture highly unsteady and complex behavior of horseshoe vortex embedded in the near wall turbulence boundary layer. ${ }^{[6]}$ Chunna le and teams numerical results concluded that conventional transporters are subject to more flow separation, but by using correct fairings at the junctions, these flow separations can be reduced, and aerodynamic properties can be modified. Apart of this, they showed that application of unstructured viscous solver provided with accurate simulation results for the wing body junction flow. A conclusion was finally made that an appropriate fairing could suppress the large flow separation at the wing body junction. ${ }^{[2], ~[10], ~[11] ~}$ Slight modification in the design of wing body junction like placing a fillet also gave good results. It has been observed that instead of preventing the separation at leading edge or horseshoe vortex formation, fillet displaces the separation flow structure away from the wing surface in such a manner that it increases the effective radius of the nose of the wing. The fillet increases the deformity of 
the time-averaged boundary layer structure produced by the stream wise legs of the horseshoe vortex and the area over which it takes place indicating that the fillet increases the size and strength of the vortex. A new nonlinear turbulence model is developed and applied to complex flow at a wing/body junction. The new model was instrumented in a threedimensional upwind compressible Navier-Stokes code by T. Chylek and team who exhibited that significant advancement to mean flow and turbulence quantities can be obtained using the nonlinear model. ${ }^{[16]}$ They also made a remark that stationing the wing at an angle of attack or varying the approach boundary-layer thickness does not appear to change the qualitative effects of the fillet on the structure of the horseshoe vortex. ${ }^{[3], ~[5], ~[14] ~}$ The experiments done by J.L Fleming stated that the position of maximum velocity directly matches the line of low shear. The flow separation is mainly affected by induced skewing and vortex induced flow near the wall. The appendage geometry and correlated pressure gradients drive the horseshoe vortex flow structure. ${ }^{[12]}$ For aircraft running at supersonic speeds, application of blunt leading edge strake have decreased the peak pressures about the wing fuselage junction, and the net area of the separated flow was alsominimized $^{[15]}$.

\section{GRID GENERATION AND SIMULATION METHODOLOGY}

Meshing is carried out using ANSYS ICEM software. Two varieties of the grid were implemented in this investigation - Grid A and Grid B. In Grid 1, the grid is generated without prismatic layers and contains 7,319,068 cells. In Grid B, prism layers are used to capture boundary layers flow. To have precise information of flow occurrences simulation of wing body junction of the roods aerofoil has been enacted. Flow modifications close to wing body terminals have been examined for Rood's aerofoil with fillet, three different types of strakes and without any fillet and strake. Three grids with expanding refinement in the boundary layer region of the junction were initiated using Grid B which are referred to as Grid B1 with ten prism layers and 7,319,068 cells, Grid B2 with 20 prismlayers and 21,915,596 cells, and Grid B3 with 40 prism layers and 13,816,221 surface grids are shown in Figure 2. NACA grid was downloaded from Morrison which helped in detailing the design and dimensions of the wing body junction. That grid was imported to ICEM CFD and was modified for current simulation. Figure 3 shows the final surface grid in the junction region for the configuration with and without the strake. Figure 4 defines the problem description and the boundarys for the computation.
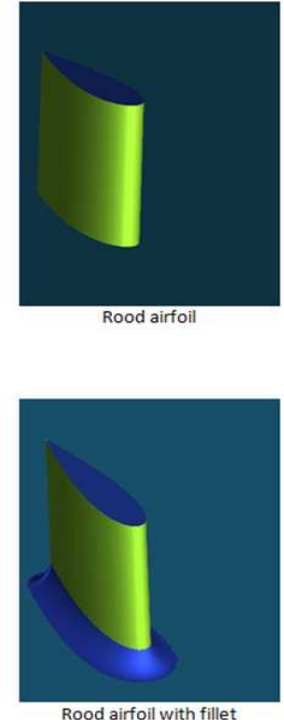
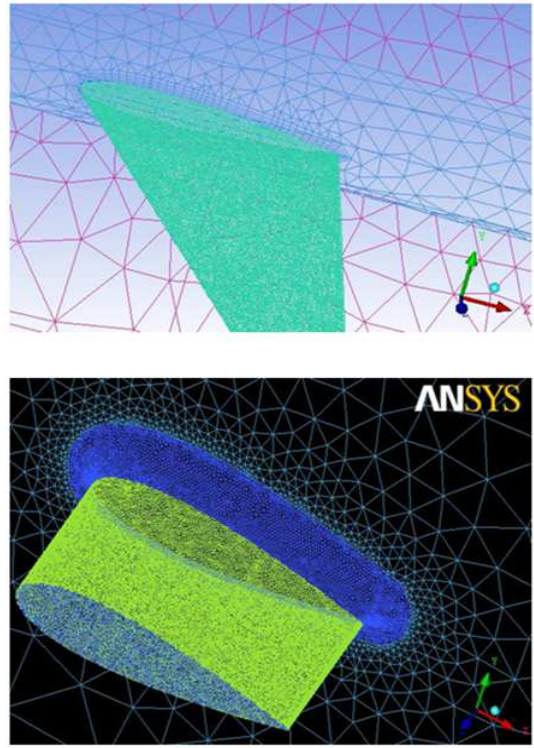


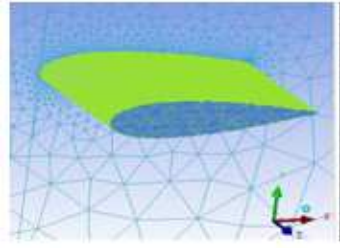

Grid A

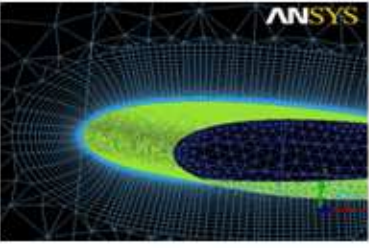

Grid B

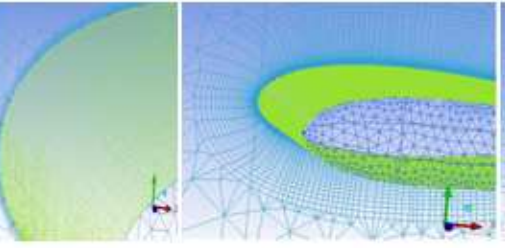

Grid B 2

Grid B 1

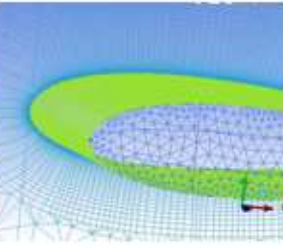

Grid B 3

Figure 2: Geometry \&Mesh of Roods Air Foil with and without Types of Grids
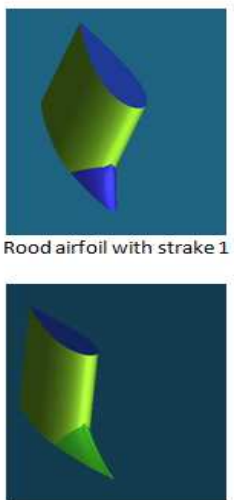
was slightly varied. Pressure minima values were closely matched at leading edge at the higher angles of attack. It was also observed that the sharpness of the two shock waves at inboard section was exaggerated in the computational solution compared with the experimental results. Figure six shows the flow over the wing body junction. In figure seven we will see the distinction within the streamlines once fairings are other to the planning of the wing body terminal. The inclusion of strakes at the situation of the wing body junction had well-tried to decrease lots of disturbance within the streamlines of the flow at the position of the wing body junction as evident in figure eight. Figure seven and eight reveal that addition of fairings, strakes, and fillets at the wing body junction bring a motivating amendment at the junction flows that helps within the reduction of drag. A remark was created that the turbulent physical phenomenon encounters a 3-dimensional separation because it proceeds towards the wing-body juncture and manages to make a vortex. This vortex has been ascertained to occur upstream and downstream of the wing-body junction. ${ }^{[18]}$

The vorticity (velocity curl) is premeditated against a vertical line in y-axis that shows a clear trend of the information bestowed for five cases velocity curl is that the primary issue for the incidence of eddies, vortices, and horseshoe vortex. Vorticity graphs with and while not strakes at an entirely different angle of attacks had been drawn in figure nine and comparison of vorticity plots of traditional roods air foil with air foil hooked up with three different styles of strakes and air foil with fillet had been drawn in figure ten. The main aim behind this is often to check the eddy generation. Altogether the various cases simulated and are available to a conclusion to implement a case with less drag. The flow trap isn't solely as a result of to 3 spatialities of the boundary layer physical phenomenon on the wall, however conjointly because of the massivevortical structure gift within the outer layer and because of the separation of the three-D turbulence physical phenomenon plagued by the adverse lateral pressure-gradients. ${ }^{[20]}$ Reynolds-stress-prompted secondary flows are envisaged to develop, and skew-prompted secondary flows are slow to be diminished by painter stresses. However, very little info concerning their decay is offered. ${ }^{[19]}$ From the vorticity (velocity curl) plots with and while not fairings has shown in on top of figures [7,9] at $\mathrm{M}=0.3,0.6$ and 0.9 with the angle of attack of five, ten and fifteen degrees. The horseshoe vortex center relocates itself far from the wing to the free stream direction because the attack angle of the wing will increase. But, at the suction aspect, it remains within the same distance from the wall. At the pressure point, the vortex center carries far from the wall. However, it remains within the same distance from the wing. ${ }^{[23]}$ While not Fairings attributable to adverse pressure gradient and interference affects the flow over wing body junction is disturbed resulting in flow separation at aft corner and vortex formation that makes a forceful increase in drag. By the addition of fairings like strake and fillet vorticity magnitude at the junction has been reduced by $50-70 \%$. 


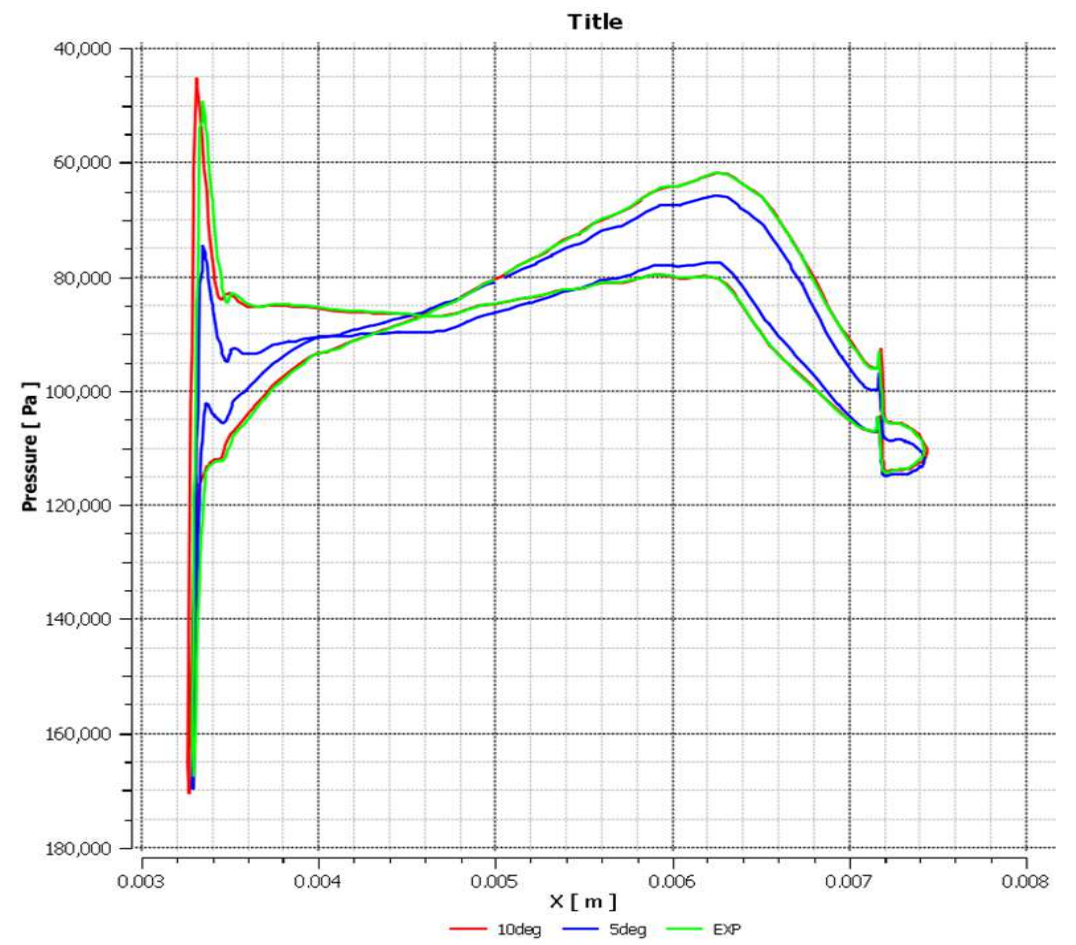

Figure 5: Wing-Surface Pressures from TM-4227 Experiment (Green), 5 Degrees AOA (blue) 10 Degreesaoa (Red) and CFD Solution

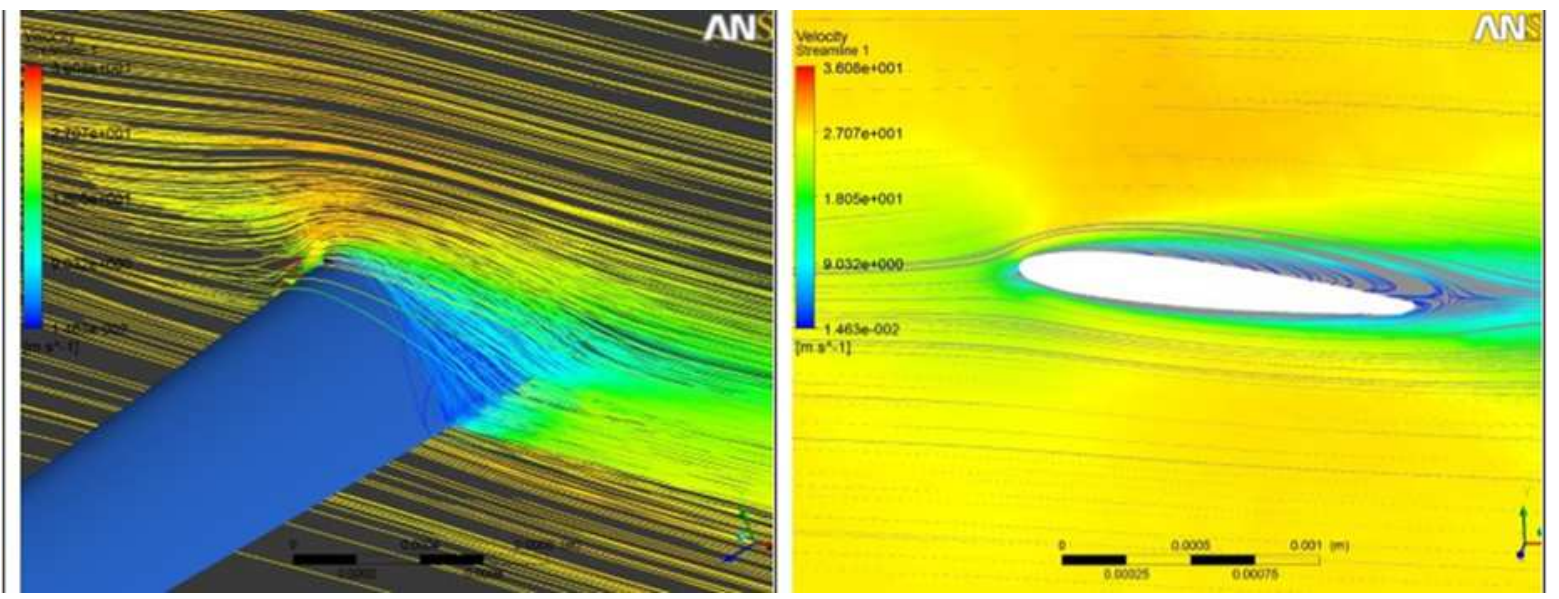

Figure 6: Streamline Pattern over Wing Body Junction

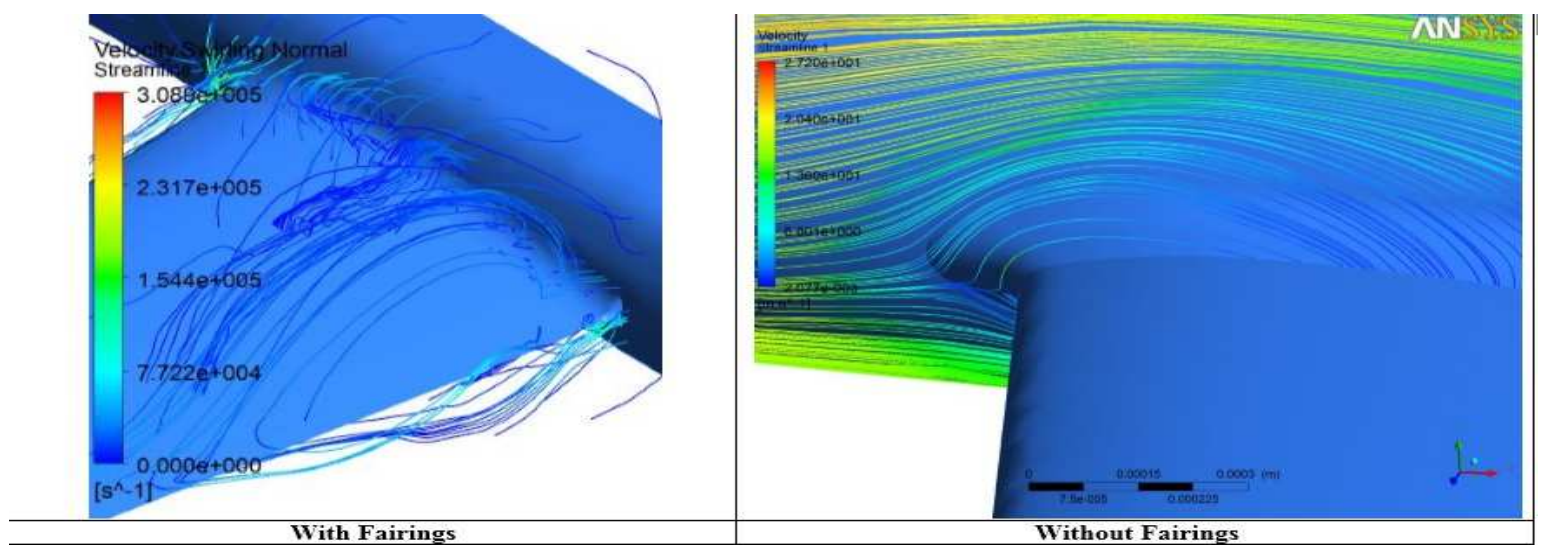

Figure 7: Contours of Flow past Wing Body Junction with and Without Fairings 


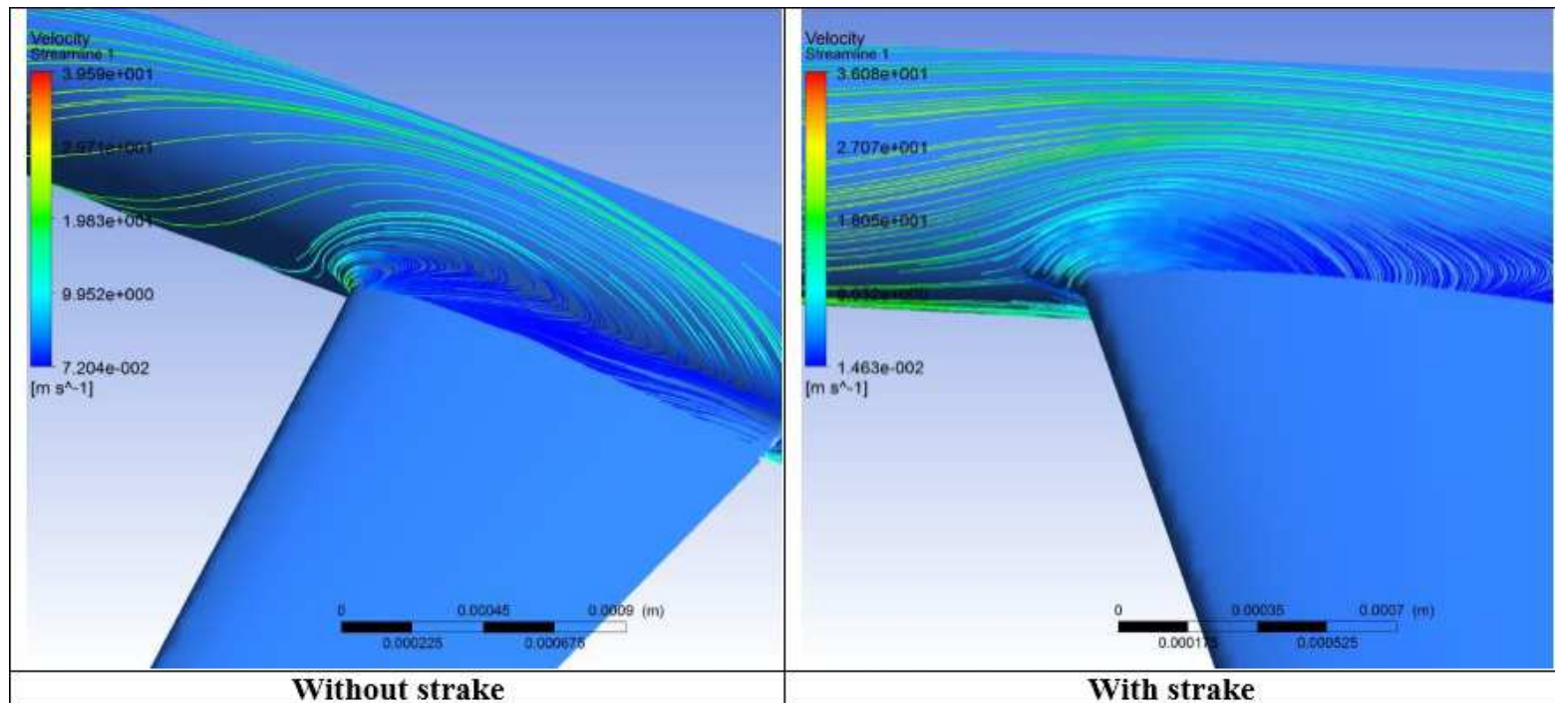

Figure 8: Contours of Flow past Wing Body Junction with and Without Strakes

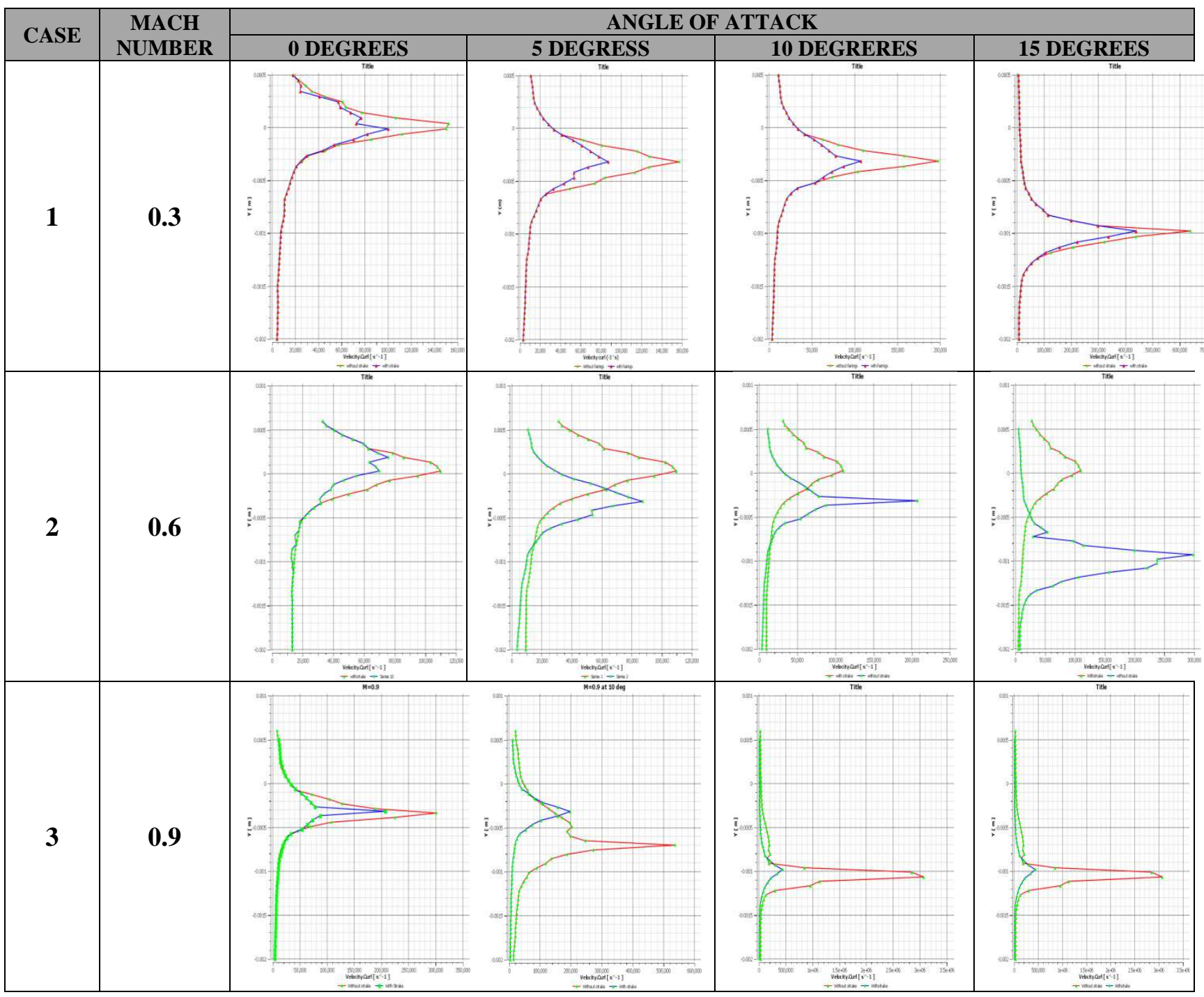

Figure 9: Vorticity Plots at different Angle of Attacks, with Strake (Blue) Without Strake (Red), X Axis Velocity Curl (/Sec) and Y Axis Length (m) 


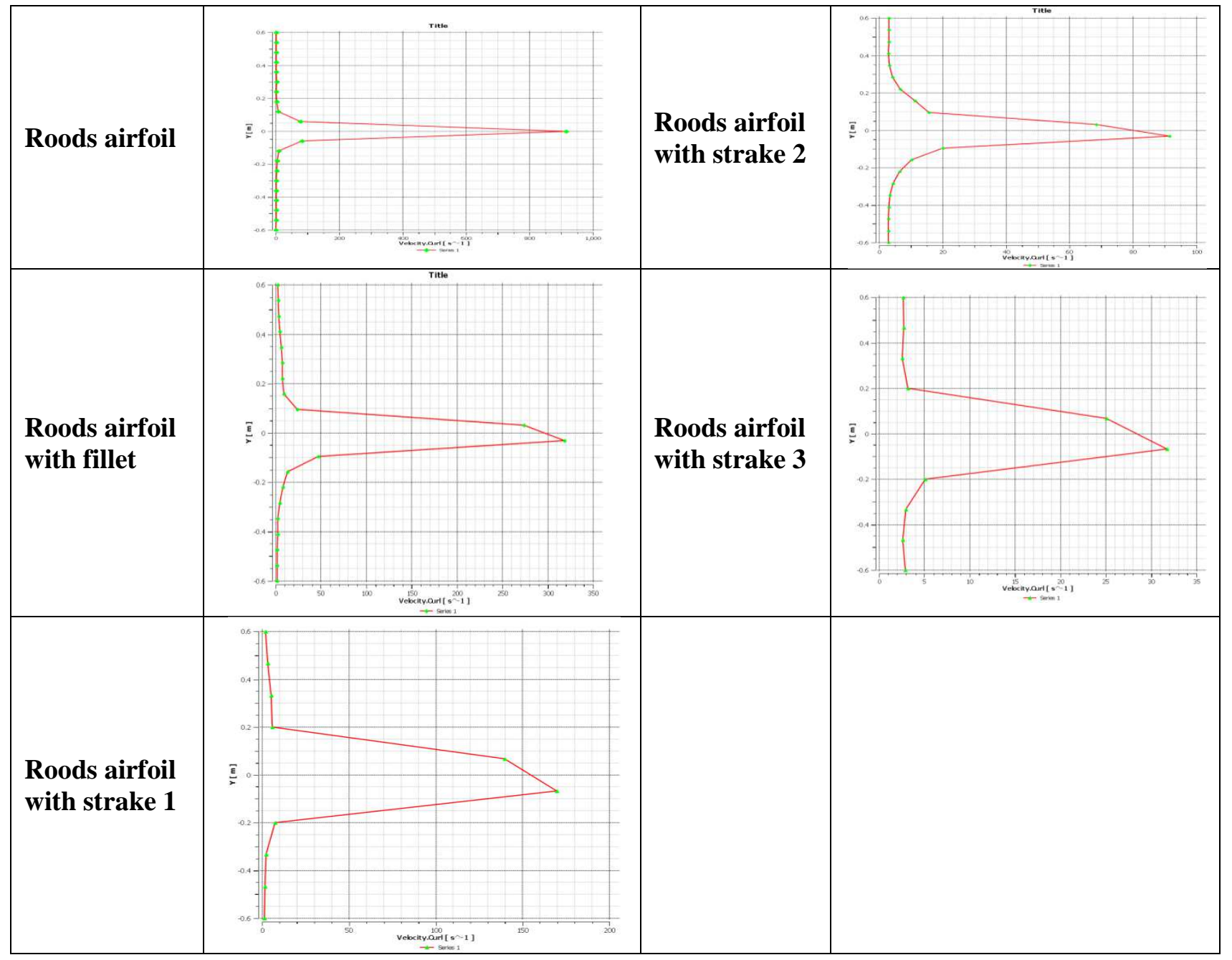

Figure 10: Vorticity Plots, with Three Types of Strakes, with and without Fillet, $X$ Axis Velocity Curl (/sec) and Y axis Length (m)

\section{CONCLUSIONS}

A computational fluid dynamic simulation, concentrating on the wing body junction had been done. The CFD results were validated, with the experiments conducted by the NASA. SST turbulence model had proved to show better simulation results, giving close resemblance to the experimental values. The SST model had accomplished, to provide a clear visualization of the flow physics at the wing body junction. Location of the horse shoe vortex in the CFD solution tallied with the experimental scenario also matched appreciably. Apart of this, a precise numerical simulation was performed by modifying the design of the wing body junction by the addition of fillets and strakes. Reduction in the aerodynamic drag due to the implementation these small modelswas proved in the simulations performed. The 3D CFX simulation concluded drag reduction due to simple design changes leading to better transonic flight efficiency.

\section{ACKNOWLEDGEMENTS}

We are very much thankful to the contribution of Dr.P.V Subba Raju, former president Aero-Mechanical department, Institute of aeronautical engineering. His technical support is acknowledged. 


\section{REFERENCES}

1. Fabien Gand, Sebastian Deck, Vincent Brunet, and Pierre Sagaut "Flow dynamics past a simplified wing body junction”, Physics of Fluids, 22, 115111 (2010), http://dx.doi.org/10.1063/1.3500697.

2. Chunna Li, Zheng in Ye and Gang Wang "Simulation of Flow Separation at the Wing-Body Junction with Different Fairings", JOURNAL OF AIRCRAFT Vol. 45, No. 1, January-February 2008, DOI: 10.2514/1.26638.

3. Song Fu, Zhixiang Xiao, Haixin Chen, Yufei Zhang, Jingbo Huang "Simulation of wing-body junction flows with hybrid RANS/LES methods", International Journal of Heat and Fluid Flow 28 (2007) 1379-1390, doi:10.1016/j.ijheatfluidflow.2007.05.007.

4. JunSok Yil and Chongam Kim “ Design Optimization of Vortex Generators for a Junction Vortex of Wing-Body Configuration by Discrete Adjoint Approach", 51st AIAA Aerospace Sciences Meeting including the New Horizons Forum and Aerospace Exposition 07 - 10 January 2013, Grapevine (Dallas/Ft. Worth Region), Texas, DOI: 10.2514/6.2013-634.

5. Bryan C. Hinson, Klaus A. Hoffmann "Parametric Exploration of Wing-Body Junction Flow Using Computational Fluid Dynamics”, JOURNAL OF AIRCRAFT, July 2015, DOI: 10.2514/1.C032985.

6. J.H. Wong, E.K. Png, “ Numerical Investigation of the Wing-Body Junction Vortex using various Large Eddy Simulation models”, 39th AIAA Fluid Dynamics Conference 22 - 25 June 2009, San Antonio, Texas, AIAA 2009-4159.

7. Fabien Gand, Vincent Brunet and Sebastien Deck "A Combined Experimental, RANS and LES Investigation of a Wing Body Junction Flow “, 40th Fluid Dynamics Conference and Exhibit 28 June - 1 July 2010, Chicago, Illinois AIAA 2010-4753.

8. Fabien Gand, Vincent Brunet and Sebastian Deck “ Experimental and Numerical Investigation of a Wing-Body Junction Flow”, AIAA JOURNAL Vol. 50, No. 12, December 2012, DOI: 10.2514/1.J051462.

9. D.D. APSLEY and M.A. LESCHZINER "Investigation of Advanced Turbulence Models for the Flow in a Generic Wing-Body Junction”, Flow, Turbulence and Combustion 67: 25-55, 2001.

10. Chunna Li, Zhengyin Ye, and Gang Wang "Simulation of Flow Separation at the Wing-Body Junction with Different Fairings”, JOURNAL OF AIRCRAFT Vol. 45, No. 1, January-February 2008.DOI: 10.2514/1.26638.

11. Li Chun na, Ye Zheng yin and Wang Gang "Simulation of the Flow Separation at the Wing-Body Junction with different Fairings “, 45th AIAA Aerospace Sciences Meeting and Exhibit 8 - 11 January 2007, Reno, Nevada AIAA 2007-1089.

12. J. L. Fleming, R. L. Simpson, and W. J. Devenport "An Experimental Study of a Turbulent Wing Body Junction and Wake Flow”, AIAA 30th Aerospace Sciences Meeting January 6-9, 1992/Reno, Nevada. AI AA-92-0434.

13. William J. Devenport and Roger L. Simpson "Flow Past a Wing-Body Junction-Experimental Evaluation of Turbulence Models”, AIAA JOURNAL Vol. 30, No. 4, April 1992. DOI: 10.2514/3.11004.

14. W. J. Devenport N. K. Agarwal M. B. Dewitz, J R. L. Simpson and K. Poddar "Effects of a Fillet on the Flow Past a WingBody Junction”, VOL. 28, NO. 12 AIAA JOURNALS DECEMBER 1990. DOI: 10.2514/3.10517.

15. S. C. BLANK "Passive techniques for controlling flow in supersonic wing / body junctions", AIAA, 1995, 1816-CP.

16. T. Chylek, L. Balakrishnan S. N. Tiwari "Investigation of turbulent separation at wing-body junction using nonlinear k-epsilon turbulence model”, AIAA Meeting Papers on Disc, January 1996 A9618391, AIAA Paper 96-0430.

17. W. J. Devenport and R. 1. Simpson "Turbulence Structure near the Nose of a Wing-Body Junction", AlAA 19th Fluid Dynamics, Plasma dynamics and Lasers Conference June 8-1 0, 1987/Honolulu, Hawaii.

18. R. Krishnamurthy, Corey D. Caglef and S. Chandra "A numerical simulation of wing-body junction flows", AIAA 1997. 
19. WILLIAM J. DEVENPORT AND ROGER L. SIMPSON "Time-dependent and time-averaged turbulence structure near the nose of a wing-body junction”, J. Fluid Mech. (1990), vol. 210, pp. 23-55.

20. M. S. Olcmen, Roger L. Simpson "Some features of a turbulent wing-body junction vortical flow", AIAA Meeting Papers on Disc, January 1997 A9715680, N00014-94-1-0092, AIAA Paper 97-0651.

21. Joongcheol Paik, Cristian Escauriaza, and Fotis Sotiropoulos "On the bimodal dynamics of the turbulent horseshoe vortex system in a wing-body junction”, Physics of Fluids (1994-present), http://dx.doi.org/10.1063/1.2716813.

22. M. S. Olcmen, Roger L. Simpson “Experimental transport-rate budgets in complex 3-D turbulent flow near a wing-body junction”, AIAA Meeting Papers on Disc, June 1996 A9636494, AIAA Paper 96-2035.

23. Takaaki Shizawa, Shinji Honami, Masahiko Yamamoto " Experimental study of horseshoe vortex at wing/body junction with attack angle by triple hot-wire”, AIAA Meeting Papers on Disc, January 1996 A9618286, AIAA Paper 96-0323.

24. O. Ozcan and M. S. Olcmen "Measurements of Turbulent Flow Behind a Wing-Body Junction “, AIAA JOURNAL VOL. 26, NO. 4, April 1988.

25. I.M.M.A. Shabaka and P. Bradshaw “Turbulent Flow Measurements in an Idealized Wing/Body Junction”, VOL. 19, NO. 2, FEBRUARY 1981 AIAA JOURNAL.

26. Satyapakash, S.S. Kumar, S.D. Jeno "Computation studies of flow field and associated aerodynamic characteristic of wing body configuration", International journal of engineering research and technology (IJERT) ISSN: 2278-0181, Vol 2 Issue 6, June 2013. 